\title{
LA RELACIÓN COMO GLOSA, GUÍA Y MEMORIA: NUEVO MÉXICO 1581-1582
}

\author{
POR \\ MAUReen Ahern \\ The Ohio State University
}

Para Alberto Escobar

... tambien guiandose por la relacion que dio Alvar Núñez Cabeza de Vaca en un libro que hizo, del viaje que trujo, saliendo la Florida a esta Nueva España ... ("Testimonio ... sobre el descubriento de dos cientas leguas adelante de las minas de Santa Bárbara" 1582. CDI: 15:89)

A los cuarenta años del recorrido de Alvar Núñez Cabeza de Cabeza por la región al oeste de Texas y norte de Chihuahua, entre 1534-1536, y del regreso de Francisco Vásquez de Coronado y sus capitanes desde Quiriva y Cíbola en 1542, la recuerdo de populosas ciudades y de grandes riquezas hacia el norte aun incitaba a la exploración de la tierra incógnita que quedaba más allá de las fronteras de Nueva España. ${ }^{1}$ Para el año de 1580, la provincia de Nueva Viscaya fue el límite de la lejana frontera minera al norte de México. La invasión de los territorios indígenas por los mineros y militares españoles, atraídos por el descubrimiento de yacimientos de plata en Zacatecas en 1546, acarreó cuarenta años de conflictos entre las distintas etnias indígenas y los militares y colonos españoles. ${ }^{2}$ En 1576, desde la Audiencia de México, el Doctor Orozco escribió al Rey: "En esta Nueva España y Nueva Galicia se tiene guerra con los indios chichimecas la cual viene de muy atrás porque puede haber treinta años poco más o menos se comenzó y no lleva término de

\footnotetext{
'Le agradezco a la Dra. Vicenta Cortés Alonso, al Renaissance and Medieval Center of the Newberry Library, y a The American Philosophical Foundation por las becas de investigación que me permitieron asistir al NEH Institute on Hispanic Paleography en 1989 e iniciar este estudio. También le agradezco a The College of Humanities, The Ohio State University por la beca que apoyó este projecto de investigación en el Archivo General de Indias, Sevilla, en 1993, donde pude examinar los documentos que fundamentan este ensayo. Gracias a Enrique Ballón y Trinidad Barrera por sus acertadas sugerencias editoriales.

${ }^{2}$ Thomas H. Naylor \& Charles W. Polzer, S.J., The Presidio and Militia on the Northern Frontier of New Spain: A Documentary History 1570-1700 (Tucson: The University of Arizona Press, 1986) 35. Phillip W. Powell, La guerra Chichimeca (1550-1600) (México: Fondo de Cultura Económica, 1977) 115-128.
} 
acabar (a lo que me parece) así por la dificultad de ella como por el modo que se ha tenido y tiene en ponerle remedio". 3

El modo en que se llevó aquella guerra era a "a fuego y a sangre" —exterminación total y condena a esclavitud perpetua — contra los llamados Chichimecas, principalmente los Guichichiles y los Zacatecos, quienes emboscaron los carros de suministro que iban para las minas y atacaron a las poblaciones y reales que se habían asentado en la región. (Naylor y Polzer 34). Los soldados que servían en esa guerra también participaron en el segundo ciclo de entradas hacia el norte, donde emplearon las mismas tácticas de violencia e intimidación en sus contactos con los amerindios de Nuevo México. Los frailes de la Orden de San Francisco habían acompañado a Francisco Vásquez de Coronado en los años cuarenta y a Francisco y Diego de Ibarro en los años sesenta en todas sus empresas de exploración. Para el año de 1575, sus misiones, establecidas en Santa Bárbara, marcaron la avanzada de la gobernación de la Nueva Viscaya, a solamante unos cuatrocientos kilómetros de los límites de las múltiples naciones llamados "Pueblo". ${ }^{4}$

Sin embargo, por aquel entonces la exploración de la frontera novohispana había cambiado radicalmente ya que en 1573 las Ordenanzas de su Majestad hechas para los nuevos descubrimientos, conquistas y pacificaciones, Julio de 1573, fueron promulgadas por el Consejo de Indias para proteger a los indios y promover la acción misionera. Prohibían el uso de la palabra 'conquista' y a partir de aquella fecha las expediciones a nuevas tierras debían tener como propósito fundamental la evangelización: "Los descubrimientos no se den con títulos y nombre de conquista; pues habiéndose de hacer con tanta paz y caridad como deseamos, no queremos que el nombre, dé ocasión ni color para que se pueda hacer fuerza ni agravio a los indios". ${ }^{5}$ Fue entonces el doble empuje de la evangelización y el deseo de hallar nuevas minas lo que inició el segundo ciclo de entradas al territorio desconocido que comenzaba a denominarse San Felipe de Nuevo México. ${ }^{6}$

Merced a las relaciones escritas por Francisco Cano, Alcalde de las minas de Mazapil en 1568, y por el Padre Miranda en 1575, ${ }^{7}$ los franciscanos en el puesto fronterizo de Santa Bárbara ya habían recibido noticias de grandes poblaciones más allá del Río Conchos y

${ }^{3}$ Archivo General de Indias, México 69, 25 nov. 1576, f. 1. Impresa también en Naylor y Polzer 55. En sucesivas referencias, Orozco.

${ }^{4}$ Oakah L. Jones Jr., Nueva Viscaya: Heartland of the Spanish Frontier (Albuquerque: The University of New Mexico Press, 1988) 27, 97-98.

${ }^{5}$ Ordenanzas ... Archivo General de Indias, Patronato, 22, 1, 4 y Colección de Documentos Inéditos, relativos al descubrimientos, conquista y organización de las antiguas posesiones españolas de América y Oceanía, sacados de los Archivos del reino y muy especialmente del de Indias, Vols. 15 y 16 (Madrid: 1871) v. 16:152 y en referencias sucesivas CDI.

${ }^{6}$ Carroll Riley, The Frontier People: The Greater Southwest in the Protohistoric Period Rev. ed. (Albuquerque: University of New Mexico Press, 1987) 23.

${ }^{7}$ Estas relaciones se encuentran el Archivo General de Indias, Patronato 22, R. 3 (Cano) y Patronato 21, N.5, R.5, (Miranda) respectivamente. También se editaron en CDI v. 19:535-538 y CDI 16:563570. Desde 1563 Francisco de Ibarra "da por nueva con testigos de vista que se a descubierto otro segund[o] México con grandisimos poblazones y con grandisima cant[idades] de pueblos ..." Traslado de una carta de México a ju[o] de la Faneda, 30 de mayo de 1563. Academia Real de la Historia, Madrid, Papeles de Jesuitas, t. 115, f. 439. 
estaban ansiosos de iniciar su labor misionera entre ellos. ${ }^{8}$ En su carta al Rey de 1576 , el oidor Orozco le había informado:

\begin{abstract}
... porque se tiene noticia que a cuarenta o cincuenta jornadas a del valle de Extremadura, hacia el nordeste, hay muchas poblaciones de gente vestida y que tienen policia donde se sospecha que hay riqueza ... Será necesario vuestra majestad dé licencia para descubrir esta tierra que la llaman el Nuevo México porque será ocasión para que vayan muchos más españoles. (Orozco, Naylor and Polzer 59)
\end{abstract}

Finalmente el 6 de junio de 1581, Fray Agustín Rodríguez y el Capitán Francisco Sánchez Chamuscado, al mando de una pequeña comitiva de tres frailes y una escolta de nueve soldados y guías indígenas, salieron de Santa Bárbara por la vía del Río Conchos hacia su confluencia con el Río Grande por el que remontaron hacia el norte. Durante los siguientes seis meses penetraron por el norte hasta Taos, al este por las grandes llanuras más allá de Pecos, donde cazaron el búfalo, y al oeste hasta los grandes pueblos de Zuni (Cíbola) y Acoma. Fray Juan de Santa María, quien intentó regresar solo a Santa Bárbara, fue asesinado en el camino. Los padres Rodríguez y López, quienes habían insistido en quedarse con los Tiwa en Puaray, también murieron después de que los soldados se marcharon y el capitán Chamuscado murió en la larga marcha de regreso. La preocupación franciscana por la seguridad de sus hermanos que se habían quedado en el norte pronto promovió una expedición de rescate al año siguiente, dirigida por Fray Bernaldino Beltrán y el comerciante cordobés Antonio de Espejo. Después de verificar la muerte de los padres, Espejo y sus soldados buscaron minas más allá de los pueblos de los Hopi o Moqui, como se los llamaba entonces, llegando hasta el centro del actual estado de Arizona. Cuando volvieron a reunirse con los frailes hubo un intento de motín y los religiosos decidieron regresar por su cuenta a Santa Bárbara. Espejo y sus soldados volvieron por el curso del Río Pecos, después de haber visitado más de sesenta pueblos de esta vasta región.

Dos textos que revelan la naturaleza conflictiva de esos tempranos encuentros impulsados por la alianza obligatoria de la evangelización y el fervor minero son la relación inédita escrita por Hernán Gallegos, escribano de la expedición de Rodríguez y Chamuscado, y el diario de campo en que Diego Peréz de Luxán apuntaba los sucesos de la expedición de Espejo. Ambos documentos evidencian una política intimidatoria de parte de los militares españoles y una solidaria resistencia indígena, jamás mencionadas por la relación oficial que Antonio Espejo publicó en Madrid y en París en 1586 en La Historia de las Cosas mas notables, Ritos y Costumbres del gran Reyno de la China de Gonzalo de Mendoza y en traducción inglesa publicada por Hackluyt en su volumen de Los viajes y navigaciones principales a fines del mismo siglo. ${ }^{9}$ Aunque los historiadores norteamericanos George

\footnotetext{
${ }^{8}$ Véase William B. Griffen, Indian Assimilation in the Franciscan Area of Nueva Vizcaya. Anthropological Papers of the University of Arizona 33 (Tucson: University of Arizona Press, 1979) para el papel clave que desempenaron los franciscanos en la aculturación de los pueblos indígenas de esta región. Ver también Alfredo Jiménez Núñez, "Etnohistoria de la Nueva Viscaya", Anales de la Universidad Hispalense 27 (1967) 39-55.

9 Antonio de Espejo, "El viaje que hizo Antonio de Espejo en el año de ochenta y tres ...". Gonzalo de Mendoza, Historia de las Cosas mas notables, Ritos y Costumbres del gran Reyno de la China
} 
Hammond y Agapito Rey publicaron la traducción inglesa de las relaciones de Gallegos y Luxán en su volumen sobre el redescubrimiento de Nuevo México en 1966 y Joseph P. Sánchez les dedica un capítulo en su estudio sobre la frontera del río abajo en $1987,{ }^{10}$ hasta el día de hoy ambas relaciones permanecen inéditas en el Archivo General de Indias en Sevilla. El presente ensayo se centra en la relación de Gallegos sobre la segunda expedición a Nuevo México durante los años 1581 y 1582 como sitio textual y paradigma de las grandes contradicciones de la empresa española que realiza los tempranos contactos con las etnias indígenas del norte. Por lo tanto, interesa también la documentación contextual de los testimonios juramentados por otros miembros de la expedición y el expediente de méritos y servicios que Gallegos remitió a la Corona en 1583.

La Relacion y conçudio del viaje y subseso que Francisco Sanchez Chamuscado con ocho soldados sus companeros hizo en el descubrimiento del nuevo Mexico y tierra nueba $(1582)^{11}$ es un discurso que inscribe a San Felipe de Nuevo México como un nuevo espacio cultural para la conversión, explotación y colonización. Ofrece gran riqueza de detalles de cómo se llevó a cabo esta triple inscripción de la nueva frontera; de cómo se conjugaban en ciertos momentos estos intereses o cómo en otras instancias esta coyuntura contradictoria de evangelizar y explotar, sembraba las semillas del amargo fracaso de ambas empresas en el siguiente siglo, cuando la ofensiva indígena proclamaba la extirpación de todo elemento español del territorio durante La Gran Rebelión de los Pueblos. ${ }^{12}$ Nuestra hipótesis de trabajo postula que las relaciones inéditas de Gallegos y Luxán desempeñaron un papel fundamental en el proceso que jugaron las representaciones escritas, orales y visuales en la configuración del imaginario de la frontera del norte en un momento de marcadas contradicciones internas entre los mismos invasores.

En este ensayo nos interesan dos aspectos claves del discurso de Gallegos. El primero es el papel que ciertas relaciones anteriores aportaron a la formación del paradigma de primer contacto con los pueblos indígenas de esta región, porque según Gallegos, la expedición resolvía todos sus encuentros mediante la apropiación de la identidad de los hijos del sol, tomada de la relación que había escrito Alvar Núñez Cabeza de Vaca sobre su paso por la misma región cuarenta años antes. En segundo lugar, nos interesa analizar la dramatización del terror que los españoles practicaban como instrumento de manipulación cultural de los mismos grupos indígenas. En resumidas cuentas, interesa examinar cómo los discursos y estrategias de contacto de la primera generación de españoles en Norteamérica jugaron un papel determinante en las experiencias de contacto de la segunda generación y cómo la consciente inclusión u omisión de relaciones anteriores sirvieron para negociar el

(Madrid, 1586) [Newberry Library, Chicago]. Richard Hackluyt, The Principal navigations, voiages, traffiques and discoueries of the English nation ... (London, 1598-1600, Rpt. Glasgow: James MacLehose and Sons, 1903-1905). Antonio de Espejo, "Relación del viage", CDI:15:101-126.

${ }^{10}$ George Hammond and Agapito Rey, The Rediscovery of New Mexico (Albuquerque: University of New Mexico Press, 1966). Joseph P. Sánchez, La Frontera del Río Abajó (Albuquerque: University of New Mexico Press, 1987).

"Archivo General de Indias, Seville, Patronato 22, r 4, f 71-100, y en referencias sucesivas Gallegos. Transcripción mía realizada de los originales examinados en AGI en 1993.

${ }_{12}$ Marc Simmons, "History of Pueblo-Spanish Relations to 1821", Handbook of North American Indians, ed. William C. Sturtevant (Washington, D.C.: Smithsonian Institution, 1979) 9:178-193. 
acceso al vasto continente del norte. A contrapelo de los propósitos expresos del partidario narrador quien persigue la configuración de un nuevo espacio idóneo para futuras empresas de colonización, las fisuras de su discurso revelan una férrea resistencia indígena donde la evangelización se prepara mediante la violencia escenificada y el trueque sólo se concede a fuerza del arcabuz.

\section{LOS TESTIMONIOS VERBALES, MATERIALES Y LINGUÚSTICOS}

Hernán Gallegos envió a la Corona dos versiones narrativas sobre el viaje. La primera fue su declaración oral tomada semanas después de su regreso en abril de 1582 por el notario de la Audiencia de México. ${ }^{13}$ La segunda fue el documento mucho más elaborado que envió al Virrey en julio del mismo año. En su primer testimonio juramentado el narrador nos ofrece importantes claves acerca de la escritura de su segunda versión, o sea, La Relación y conçudio ...

Ante el notario real, Gallegos declara ser nativo de Sevilla, de sólo veinticinco años de edad; había pasado nueve años en la frontera minera de Nueva Viscaya donde sirvió como soldado bajo el mando de Diego de Ibarra en las minas en Mazapil y en las campañas fronterizas contra los indios chichimecas (CDI 15: 88). También declara que ha buscado minas a su propio costo, y como muchos soldados de su época, había participado en la cacería de indios más allá de Santa Bárbara, lo que ya era práctica común so pretexto de perseguir a los indios salteadores de caminos. ${ }^{14}$ Fue en aquellas salidas cuando un indio cautivo le contó al joven sevillano que hacia el norte:

abia muy grandes poblaciones de indios; que tenian algodon y acian mantas de que se vestian; é que se sustentaban de maiz é gallinas de la tierra, y frisoles y calabazas, y carne de vaca; y que esto le dió deseo á él y los demas, de entrar la tierra dentro, y tambien guiandose por la relacion que dió Alvar Núñez Cabeza de Vaca en un libro que hizo, del viage que trujo, saliendo la Florida a esta Nueva España (CDI 15: 89). [el énfasis es nuestro]

A esta declaración el notario agregó: "este declarante tiene hecho un libro, escripto de su mano, donde hace relacion de todo este viaje que ha hecho; el cual tiene entregado á su

13 "Testimonio dado en Méjico sobre el descubrimiento de doscientas leguas adelante de las minas de Santa Bárbara.1582", CDI: 15: 88-95; AGI, Patronato 22, R. 5 [en abril de 1993 faltaba el expediente].

${ }^{14}$ El oidor Orozco también había mencionado en su carta al Rey de 25 nov. de 1576 sobre la cacería de indios: "Pero los capitanes y soldados que en esta guerra han entendido, el premio y salario que han tenido han sido las presas que se han hecho en los Indios, vendiéndolos por esclavos por algún tiempo que se les ha permitido, precediendo los procesos y culpas por donde los condenaron" (Orozco, Naylor y Polzer 46). Según Silvio Zavala, el problema de la esclavitud había avanzado hacia el norte donde "... volvemos a encontrar: soldados interesados en el cautiverio de los indios; religiosos que denuncian los abusos; leyes de protección de la libertad que las autoridades superiores tratan de hacer cumplir frente a la obstinación de autoridades provinciales y particulares que sacan provecho de ignorarlas", Los esclavos indios en Nueva España (México, D.F.: Edición de El Colegio Nacional, 1967) 224-225. 
Excelencia: que todo lo en él contenido es verdad; por que lo fué escribiendo como lo iba viendo y por andar en ello" (CDI 15: 95). Aquel "libro escrito de su mano" era la Relacion y conçudio que Gallegos firmó y copió el 8 de julio de 1582, dirigida al Virrey Don Lorenzo Suárez de Mendoza, donde el autor se identifica a sí mismo como el escribano y descubridor de la expedición. Sin embargo, en la última hoja del grueso expediente de la información de méritos y servicios de Hernán Gallegos en el Archivo General de Indias, observamos que al despacharlo al Rey, los Oidores de la Audiencia de México dejaron traslucir su escepticismo, en renglones que hablan claro los "dicen que", "parece", "solamente" y "que dicen", apuntados en letras grandes:

Her[nan]do Gallegos hico informacion en esta Real Aud[ienci]a de como a servido a su mag[estad] siendo sold[ado] en esta tierra contra los Indios chichimecos y tambien se ocupo un año en cierto descubrimiento que dicen se hico de una probincia po[blada] de gente vestida y con buenas casas con [roto] parece por la información. En esta real aud[ienci]a. lo conocemos solamente por uno de l[os] soldados que dicen que hico el descubrimien[to] arriba dicho V[uestra] m[erced] le puede hacer la m[erced] q[ue] fuese serbido ${ }^{15}$ [el énfasis es nuestro]

El prólogo de la Relación y conçudio ... deja en claro que Gallegos lo compone como adelanto de la petición que él haría en Madrid al año siguiente al solicitar la comisión real para la exploración y pacificación de las nuevas tierras. Aquí Gallegos expone su causa con toda la rétorica política del día que se requiere: "determinamos ... hazer el dicho viaje llebando por ultimo fin el servicio de dios nro sr y que su ley e ebangelio se predicase a toda criatura y que la Real corona de Castilla se aumentase" (Gallegos 71R). Para el narrador, la salida de la comitiva de San Gregorio ofrece la ocasión de elevar el viaje a alturas épicas y formular el aplauso retórico del valor, el martirio y el ejemplo literario de "los nuebe hijos de la fama", ${ }^{16}$ quienes ofrecen una analogía idónea para los nueve soldados de la escolta.

... fortalecidos con la esperiencia del premio eterno y temporal que esperabamos a ymitacion de los nuebe hijos de la fama con animo liberado de morir o descubrir la tierra deseada. Proseguimos el dicho viaje hasta llegar a ella en el qual aviendo yo visto las cosas notables y sucesos de aqueste descubrim[ient]o e proui[ci]a ... (Gallegos 71V)

El narrador también comenta que le ha motivado dedicar este informe al Virrey el ejemplo de la pobre viuda del Evangelio, ${ }^{17}$ quien fue alabada por el Señor por ofrecer sus dos monedas en el templo y que no porque dió poco fue menos preciada sino en más tenida:

\footnotetext{
${ }^{15}$ Concluye con cinco firmas, entre ellas las de los Doctores Orozco, López, y Robles (AGI, Patronato, 77, n. 1, R. 7, la).

16 "Los nuevo hombres de la fama fueron: tres judíos - Josea, Davíd y Judas Maccabeus; tres gentiles -Alejandro, Héctor y Julio César; tres cristianos -El Rey Arturo, Carlomagno y Godfrey de Bouillón. La novela, Le triomphe des neuf preux_(Dabbeville, 1487; Paris, 1507) se tradujo a espanol como El triumpho de los nueve de la fama, y fue impresa en Lisboa, en 1530, y en Valencia en 1532. Posteriormente hubo muchas otras ediciones". Hammond and Rey 68.

${ }^{17}$ Del Evangelio de Marcos, cap. 12, verso 42.
} 
a cuya meditaçion hallandome con dos cornadillos de caudal los e ofrecido y aber jurado en este suseso a $\mathrm{V}$ [exa] atendiendo a que yo de todo lo que tengo y a la voluntad con que lo e ofrecido lo reciba debajo de su proteccion pues de el neg[ocio]o que se trata le cabe a V[uestra Excelenci]a se a descubierto lo que tanto se deseaba por los pasados no sin particular providencia de dios ... (Gallegos $71 \mathrm{~V}$ )

El prólogo coloca entonces el marco épico y providencial de heroismo, el servicio a Dios y al rey, el sacrificio en la tradición caballeresca y la emulación del evangelio, en una gran reverencia a su destinatario el virrey, quien habrá de compartir la gloria anticipada y la providencia especial de Dios. Pues, de hecho, un puñado de españoles ha logrado lo que no pudieron hacer quinientos soldados a paga de la corona. El entramado retórico de los sucesos cuya narración tiene como fin el nombramiento de Gallegos como Gobernador de Nuevo México encierra tanto el inicio como el fin de su informe, y condiciona al lector para que se muestre favorable ante los sucesos que relata el narrador-escribano-soldadotestigo. No obstante, Gallegos jamás mencionó las exploraciones de Francisco Vásquez de Coronado sobre el mismo territorio entre los años de 1540 a 1542.

Aquel otro precursor de Gallegos en este mismo territorio, Alvar Núñez Cabeza de Vaca, había escrito en el "Prohemio" de su relación en 1542, que su escritura de las experiencias que había sobrevivido: “... pues éste sólo es el que vn hombre que salió desnudo pudo sacar consigo". ${ }^{18}$ En cambio, para presentar el testimonio de su recorrido ante la audiencia, Gallegos y su compañero de armas, Pedro de Bustamante, sacaron de sus mochilas pruebas materiales para el Virrey: trozos de mineral, ropa, cueros, carne de búfalo, y sal para hacer constar sus declaraciones, atando de esta manera a sus palabras la evidencia física cuando muestra los referentes materiales de su discurso para suplir la insuficiencia del lenguaje ante la realidad del gran norte desconocido (Gallegos 100R). ${ }^{19}$

El primer capítulo de la Relación continúa la misma práctica en términos numéricos. El sujeto enunciador "Yo" y el "ojo" del viajero toman las medidas numéricas para hacer "ver" a su destinatario: es decir, miden y apuntan el número de leguas y los grados de longitud y latitud del avance; el número de casas en cada pueblo y cuántos altos tenían, el número de búfalos que vieron y que mataron y el número de indígenas que salieron a recibirlos. De ahí que cuantificar las cosas es una manera de infundir verosimilitud en el lector. Medir es también una manera de traducir al otro. También lo son las glosas de las voces indígenas que el narrador intercala al final del primer capítulo donde cuidadosamente anotó tres palabras tomadas de la lengua del primer grupo nativo que encontraron .... "esta gente llama al agua bad, y al mais sonet y tienen por nombre Yoslli" (Gallegos 72R). En el Capítulo Nueve, entre los Tiwa, Gallegos apunta: "[esta gente] llama al mayz cunque y

\footnotetext{
${ }^{18}$ Alvar Núñez Cabeza de Vaca, La relación y comentarios del gouernador Aluar Nunez cabeza de Vaca de lo acaescido en las dos jornadas que hizo a las Indias (Valladolid, (1542), 1555). Los Naufragios, Enrique Pupo-Walker, editor (Madrid: Editorial Castalia, 1992) 180.

19 "fueron ante su excelencia a dalles relaçion del dicho viaje segun y como se auvia hecho y lo truxeron y presentaron de lo que en la tierra auia para muestra que era de la ropa y carne de las bacas y sal de las salinas y metales de las minas que se descubrieron y ay en la tierra que salieron algunos de los a razon de a veinte marcos por quintal de tierra dimos tambien los chicubites en que comen y de la loça que en la dicha poblazon hazen que es como la de la Nueva España" (Gallegos 100R).
} 
al agua pica y la gallina dire y a la muger Ayu y quando quieren beber, dizen sesu ... Es lengua muy facil de deprender y la gente mas domestica y trabajadora y los mas lindos labradores que ay en la Nueva España y tanto que si truxeramos lengua se tornaran cristianos parte dellos porque es gente muy entendida y de delicado servicio" (Gallegos 80R). Como signos extraídos del mundo del otro para significarse en el mundo del lector, la precisión lingüística aumenta la credibilidad del lector en el narrador quien también ofrece su testimonio oral, o sea, su oído. Notamos, además, que los elementos del léxico básico que Gallegos recoge para varias etnias se toman siempre de los mismos campos semánticos: el agua, los alimentos, el ser humano, un artículo de trueque y el vocablo que cada tribu utiliza para nombrarse. Estas glosas serán muy útiles para los contactos futuros, ya sean de evangelización o de comercio, porque constituyen un vocabulario de comunicación básica mediante el cual el futuro viajero español podría avanzar por el territorio. ${ }^{20}$

\section{Guión de CONTACTO: Los HuOS DEL Sol}

Al remontar el Río Conchos, los españoles ingresan en el territorio desconocido a lo largo de sus orillas donde se encuentran con tribus cuyas lenguas no conocían sus guías de habla nahua. Los Cabris salieron a recibirlos con regalos, deseos de amistad y la esperanza de que los foráneos les ayudaran a vencer a sus enemigos. No obstante, muchos grupos habían huido a la sierra por temor a ser capturados. ${ }^{21}$ Sin embargo, en versión de Gallegos, la respuesta de los españoles a los Cabris varía dentro de una sola oración, desde una oferta de amistad y protección a una amenaza directa de matar a estas gentes si no se comportaban bien ante los invasores. Si ellos querían vengar a sus parientes que habían sido capturados por los soldados españoles, debían declararlo rápidamente. Sin embargo, a este grupo nativo ya tan aterrorizado por los cazadores de esclavos, se les indujo un nuevo temor.

Y este camino que con los naturales mostraron los dichos españoles fue mas porque los naturales les tuviesen miedo y corriese la voz y se dispararon muchos arcabuces y visto el despararse los arcabuzes los naturales se amedrentaron mucho y respondieron que ellos no queria tener enemistad con los españoles si no antes ser sus amigos y que antes

\footnotetext{
20 "El lenguaje era el rasgo principal que distinguía a los indios pueblo. En 1500 se hablaban siete lenguas que pertenecían a cuatro familias linguísticas: Tanoa, Keres, Zuni, y Uto-Azteca Los pueblos de de la familia Tano comprendían los Tiwa, los Tewa, los Piro y los Towa, hablantes que vivían principalmente en la orillas del Río Grande o sus tributarios". Ramón A. Gutiérrez, When Jesus Came, the Corn Mothers Went Away: Marriage, Sexuality, and Power in New Mexico, 15001846 (Stanford: Stanford University Press, 1991) xxv. Forbes compara las voces transcritas por Gallegos con sus formas equivalentes en la lengua Tiwa de Isleta y la de los Tewa del pueblo de San Ildefonso y las vincula con los Tewa del grupo más norteño. Jack D. Forbes, Apache, Navaho and Spaniard (Norman: The University of Oklahoma Press, 1960) 51.

${ }^{21}$ Forbes los identifica como Julimes (47) y Hammond y Rey como Cholomes (19). Los capitanes de la expediciones de Francisco y Deigo de Ibarra por los años 1564 y 1565 habían tomado mucha gente de esta región como esclavos. Además la terrible epidemia de 1576 había causado grandes bajas entre la población indígena resultando en la escasez de trabajadores libres para las minas. Véase Daniel R. Reff, Disease, Depopulation and Culture Change in Northwestern New Spain, 1518-1764 (Salt Lake City: University of Utah Press, 1991).
} 
querian ser foborecidos en sus guerras ... y quiso dios poner en estos naturales y en los demas el dicho miedo porque bien entendian los espanoles susodichos que ellos no eran bastantes para resistir a tanto numero de gente si no era con ayuda del Senor y con esta confiança, se avian puesto a hazer la dicha jornada (Gallegos 73R) [el énfasis es nuestro].

En este pasaje escuchamos la voice-over del sujeto narrador que manipula la escena que nos presenta para que la "veamos" cuando interpreta los sucesos como la voluntad de Dios. El temor que resulta de esta táctica de intimidación es ahora legitimado como un acto de Dios que les permitió a los exploradores sobrevivir una expedición que ha sido favorecida por la asistencia divina desde su comienzo. El narrador le "dice" al lector lo que "significan" aquellos sucesos, de la misma manera como la técnica de voice-over en el cine nos "dice" a los espectadores lo que "vemos", un hablante invisible desde un tiempo y un lugar distinto a los que se proyectan en la pantalla, que sirve como medio para ganarse nuestra comprensión e identificación, tal como nos explica Kosloff en su estudio sobre voice-over en el cine contemporáneo. ${ }^{22}$

Pero cuando los españoles levantaron cruces en sus pueblos, Gallegos nos informa que: "los naturales recivieron mucho contento y alçaron las manos hazya el sol porque les avian dicho que eran hijos de el sol ..." (73R). Es a partir de este encuentro inicial que se ensaya un guión para el contacto inicial: ofertas de alianza contra los enemigos y protección contra los españoles que tomaban esclavos; amenaza de muerte si los invasores eran heridos; disparo de arcabuces, e identificación de los españoles por los indios como los Hijos del Sol. A cambio de ello, los españoles reciben información acerca de populosas comunidades asentadas en el norte con grandes casas y abundancia de alimento y vestimenta de algodón. Ahora los españoles erigen su propio signo de posesión, la cruz, y de inmediato envían mensajes a aquella nación que, "nosotros veniamos para restaurar la paz entre estas gentes" (Gallegos 73V). En el Libro XII del Códice Florentino, el Padre Sahagún consignó la narración iconográfica de las mismas estrategias que Hernán Cortés había empleado en los primeros días de su llegada a las costas de México: oferta de alianzas e intimidación de los embajadores nativos con armas y caballos. ${ }^{23}$ Alvar Núñez Cabeza de Vaca, Fray Marcos de Niza y Fernando de Alarcón también habían apuntado episodios semejantes cuando relataron cómo los indígenas de la tierra adentro proclamaron a los forasteros ser Hijos del Sol y los iniciaron en los rituales de curación y regalos, como hemos analizado en otras ocasiones. ${ }^{24}$ La expedición de Rodríguez y Chamuscado parece seguir muy estrechamente

\footnotetext{
${ }^{22}$ Sarah Kosloff, Invisible Storytellers: Voice-Over Narration in American Fiction Film (Berkeley/ Los Angeles/London: University of Calfiornia Press, 1988) 5, 65.

${ }^{23}$ Fray Bernardino de Sahagún, Florentine Codex: General History of the Things of New Spain, Book 12. The Conquest of Mexico, 13. vols. trads. Arthur J.O. Anderson and Charles E. Dibble (Santa Fe: The University of New Mexico Press, Monographs of the School of American Research, 1975) V.13: 15-16.

${ }^{24}$ Maureen Ahern, "Cruz y calabaza: La apropriación del signo en las relaciones de Alvar Núnez Cabeza de Vaca y de Fray Marcos de Niza", Notas y comentarios sobre Alvar Núñez Cabeza de Vaca. Margo Glantz, coord. (México: Editorial Grijalbo, 1993) 351-377. "Ĺa articulación de la alteridad en la frontera del norte: Relatione della navigatione \& scoperta de Fernando de Alarcón”,
} 
estas mismas relaciones que fueron escritas cuatro décadas antes, utlizándolas como una especie de guía de viajero y guión para el contacto. En la confluencia del Río Conchos con el Río Grande, encuentran una nación guerrera que vivía en "un poblado permanente de casas similares a las de los mexicanos". Y es allí donde es montada en escena la primera lección evangelizadora:

embiamos a llamar mucha gente y luego vinieron y como la gente de atras estaba ya ynpuesta en que besaban la mano a los padres religiosos que con nosotros traiamos y para que lo hizieran se la besabamos primero para que los naturales tomasen exemplos y los naturales luego besaban la mano y alçaban las manos al cielo y asoplaban hazia arriba porque les dimos a entender que aquellos padres que llebabamos con nosostros eran hijos de el sol y que avian caido del cielo y que nosotros eramos sus hijos y ellos asi lo creyeron (75R).

Ahora se usurpa la identidad de los Hijos del Sol para trasladarla a los frailes, con la novedad de representar a los soldados como sus hijos y de dramatizar el acto de reverencia que se quiere imponer.

\section{GUIONES ANTERIORES Y PAPELES NUEVOS}

En el mismo lugar de La Junta de los Ríos, Rodríguez y Chamuscado se enteraron de que trece días río arriba hacia el interior vivía gente vestida que cultivaba la tierra y habitaba en casas grandes y altas con escaleras. Pero decidieron que no eran mexicanos porque "[fue] por la relacion de los que avian entrado a descubrir avian coronistado que en nuestro Poder llevabamos y nos dieron a entender que la dicha gente poblada que era gente muy valiente y que era mucha pero no por eso nos falto el animo para pasar adelante" (Gallegos 75V). La declaración juramentada que prestó Gallegos explicítamente identificó esta relación que los exploradores llevaban como la de Alvar Núñez Cabeza de Vaca (cuya Relación o Naufragios había sido publicada en Zamora, España en 1542 y de nuevo en Valladolid en 1555). Quizás llevaban también la Relación del descubrimiento de la Siete Ciudades escrita por Fray Marcos de Niza en 1539, o la relación que Fernando de Alarcón remitió al Virrey Mendoza sobre sus navegaciones por el Río Colorado en 1540, ${ }^{25}$ que había publicado Ramusio en 1556 en el tercer tomo de su Navigationi et Viaggi y que Oviedo incluyó en su Historia general y natural de Las Indias (Libro XL:1).

Con la promulgación española de su nueva identidad se intensifica la actuación ritual de los indígenas y por consiguiente se hacen aún más abundantes los obsequios en varias escenas que nos recuerdan los episodios que narra Núñez Cabeza de Vaca sobre su acompañamiento de muchedumbres que festejaban a los sobrevivientes con bailes y regalos

Crítica y descolonización: El sujeto colonial en la cultura latinoamericana, Beatriz González Stephen y Lúcia Helena Costigan, eds. (Caracas: Academia Nacional de la Historia de Venezuela y The Ohio State University, 1992) 167-185.

${ }^{25}$ Véase Maureen Ahern, "The Certification of Cíbola: Discursive Strategies in La relación del descubrimiento de las siete ciudades by Fray Marcos de Niza (1539)", Dispositio 14, 36-38 (1989): 303-313 y Maureen Ahern, "a articulación de la alteridad en la frontera del norte ..." 
de comida. (Gallegos 76R) De esta manera la identidad apropriada de los Hijos del Sol también permite que esta segunda expedición obtenga alimentos y participe en el sistema de intercambio ritual que Cabeza de Vaca ya había relatado. ${ }^{26} \mathrm{Y}$ es precisamente ahora que los compañeros de Gallegos indagan explícitamente sobre los contactos anteriores con sus paisanos.

y preguntandoles que si avian pasado por alli algunos hombres como nosotros dixeron que mucho tiempo abia que avian pasado por alli quatro cristianos y por las señas que nos dieron entendimos clara y abiertamente sera albaro Nuñez cabeza de vaca porque segun su Relacion paso por esta gente el rio [sic] aunque agora llebabamos mas relacion de cosas muy pulidas y de mucha ymportancia que no llebaba cabesa de vaca por lo qual entendimos ser cosa guiada por la mano de el senor porque tan pocos hombres atreberse a entrar entre tanta multitud de gente barbara e ydolatradora porque no auia dia que marchabamos por el dicho Rio de la concepcion que no teniamos con nosotros mas de trezientas animas de dia y de noche pero como son cosas guiadas por mano de el Señor tomamos grande esperança de salir con qualquier vitoria y predicar el evangelio pues era la bandera que nosotros llebamos ... (Gallegos 76R y 76V).

Gallegos nunca pierde la oportunidad de incorporar la providencia para legitimizar los sucesos que relata. Aquí le sirve para convertir los hechos de un pequeño grupo de nueve soldados y tres frailes en hazañas trascendentales, marcadas por la mano de Dios, calificando la ocasión como extraordinaria, estrategia que propone engrandecer la expedición y demostrar su fiel cumplimiento de las Ordenanzas vigentes (CD 16:15). Nos interesa también notar cómo el narrador condiciona la recepción de su texto para el lector cuando nos informa que su crónica es ahora más larga y concisa que la relación de Cabeza de Vaca; aunque en realidad no fue así. Este intento de desacreditar la relación de Cabeza de Vaca para ensalzar el valor de su propia historia, es un ejemplo más de la intensa manipulación que este sujeto les impone tanto a su objeto narrado como a su lector. También descuenta otras expediciones anteriores: “... pues antes de agora avian entrado mucha cantidad de hombres españoles con comisiones muy bastantes de los visorreyes de la Nueva España en busca de este dicho descubrimiento y poblazion y no hauian topado con ella" (Gallegos 79V). Este comentario alude a las expediciones de Francisco Vázquez de Coronado de 1540 a 1542 y de las de Francisco de Ibarra de 1563 a 1565, cuyas exploraciones habían terminado en grandes disilusiones. Sin embargo, en el caso de Coronado no fue cierto que no hubiera descubierto las poblaciones de los grupos Pueblos, porque efectivamente su ejército había vivido entre ellos por casi dos años, y existían detalladas cartas al Virrey y al Rey al respecto. ${ }^{27} \mathrm{Ni}$ es lógico suponer que la memoria de un ejército de más de mil quinientos soldados e indígenas se hubiera borrado tan fácilmente entre la siguiente generación de soldados. Sin embargo, si uno proponía obtener la comisión real para organizar otra entrada de asentamiento en la misma región, era conveniente

26. Véase Ahern, "Cruz y calabaza ..." y también Gutiérrez sobre la gran importancia social del obsequio recíproco entre los grupos Pueblo, 9.

${ }^{27}$ Véanse los muchos documentos recogidos en George Hammand and Agapito Rey, eds. and trans. Narratives of the Coronado Expedition: 1540-1542 (Albuquerque: The University of New Mexico Press, 1940). 
informar que no la habían encontrado las anteriores. Gallegos reconstruye las expediciones de su propio pasado reciente para construir un futuro suyo necesario para sí mismo y para Nuevo México. Mediante su memoria selectiva se acuerda de Cabeza de Vaca para apropriarse de un guión que efectuara el contacto mediante la dramatización. Pero se olvida del recorrido más reciente por el mismo territorio del ejército de Vásquez de Coronado, para conferirse el lugar de "primer descubridor". Curiosamente muchos historiadores han aceptado la declaración de Gallegos tal cual la decía. A nuestro parecer es más lógico considerarla a la luz de sus evidentes contradicciones internas, como señala Dolores Gunnerson. Ella argumenta que algunas declaraciones de Gallegos, "indican que el Virrey estaba deseoso de patrocinar descubrimientos importantes durante su administración o conspiraba en hacer caso omiso de los derechos de exploración que le pertenecían a Diego de Ibarra como Gobernador de Nueva Viscaya". ${ }^{28}$ Esto explicaría, al menos en parte, la fuerte dosis de providencialismo que Gallegos siempre aprovecha, el designarse a sí mismo "el primer descubridor" de Nuevo México y sus extensas adulaciones al Virrey en el prólogo y epílogo.

\section{LA DRAMATIZACIÓN DEL TERROR}

Conforme avanzan tierra adentro, los soldados aprovechan para convertir la caza del búfalo en un poderoso mensaje visual: envían a su guía cargado de carne a la ranchería de los apache - tribu que cazaba el búfalo con arcos y flechas- para que vieran los resultados de la gran matanza de reses que habían lograda con los arcabuces.

Tanto a la mitad del discurso como del viaje, el movimiento lineal de la exposición del itinerario para bruscamente y enfoca la atención del lector en una serie de actuaciones dramáticas, diseñadas explícitamente para inculcar el terror en el espectador. El narrador amplía las escenas de una ejecución fingida que se convierte en poderoso instrumento de terror para amedrentar la numerosa población nativa. En segundo lugar, esta maniobra logrará colocar a los frailes en el nuevo papel de defensores de los amerindios con el fin de favorecer las futuras labores con ellos. Después de matar a Fray Juan de Santa María, cuando intentó regresar solo a México para dar la buena nueva del descubrimiento y traer más frailes para ayudarlos en la gran conversión que se anticipaba, Gallegos explica que los indios ya no los tenían por inmortales (Gallegos 87R) y, por lo tanto, los once forasteros corrían gran peligro. En el momento que la tropa inició su retirada hacia Santa Bárbara, algunos indios del pueblo de Malagón robaron y mataron tres caballos. Los españoles "entraron en el pueblo en orden de batalla", pero los habitantes respondieron que ellos no habían hecho tal fechoría. Los soldados descargaron sus arcabuces y los aterrados habitantes huyeron hacia sus casas. Cuando Hernán Gallegos y Pedro de Bustamante encontraron trozos de carne de caballo en dos casas, sus compañeros dispararon los arcabuces una vez más: "y luego cabalgaron los dichos Hernan Gallegos y Pedro de Bustamante y todos los cinco campañeros con la carne de los caballos en las manos" (Gallegos 88V), ordenando que les entregasen a los culpables. El narrador construye con lujo de detalles el dramático

\footnotetext{
${ }^{28}$ Dolores Gunnerson, The Jicarilla Apaches; A Study in Survival (Dekalb: The Northern Illinois University Press, 1947) 49.
} 
enfrentamiento de las tropas españolas que sacudían la ensangrentada carne de caballo en medio de la plaza. Atacaron al pueblo de nuevo y Bustamante capturó a dos indios, a quienes el capitán Chamuscado mandó cortarles la cabeza. Mas, ahora, los soldados decidieron teatralizar el terror. En el centro de la plaza se colocó un tajadero para cortarle la cabeza a los prisioneros con un machete de hierro. La escena vale la pena considerarla en su segmento textual completo:

se hizo segun y como se avia mandado aunque se determino de hazerse que como los padres religiosos se avian determinado de quedar en aquella poblazon de que al tiempo que se fuesen a cortar las cabezas a los dichos yndios saliesen ellos de atraves y arremetiesen con nosotros y que nos les quitasen para que les tomasen amor pues se avian querido y determinado quedar en aquella tierra lo cual se hizo en forma al tiempo que se les yba a cortar las cabecas salieron de manga los padres religiosos y quitaron los yndios de el dicho paso y como mostramos que se los ybamos a quitar luego los yndios que alli estaban echaron mano de los dichos padres y de los yndios y los llebavan a sus casas de el mucho socorro que avian hallado en los religiosos de esto que se hizo y determino hacer los naturales nos tomaron tanto miedo que era para espantar que tremblaban y permitiólo dios de el cielo que nosotros poco fuerca eramos y luego otro dia de manana vinieron del pueblo de Malagon muchos yndios cargados de mucha comida y gallinas de la tierra para nuestro comer y que no estubiesemos enojados con ellos porque no lo harian mas y que ellos de alli adelante mirarian y buscarian los caballos que ninguno se perderia y que ellos eran nuestros amigos de lo qual tomamos mucho contento aunque no se lo dabamos a entender para que ellos y los demas nos tubiesen mas miedo de lo que nos temian ... y si antes de esto nos mostraban mucha amistad mucha mas nos mostraban entonces juntamente con el miedo que tenian benimos a entender claramente de ellos propios que nos querian matar estubimos determinado de acometerles a matarlos y quemarles algunos pueblos pequeños aunque sobre ello muriessemos porque tuviesen miedo a los españoles (Gallegos 89V-90R).

\section{¿UNA EJECUCIÓN FINGIDA?}

Aunque el narrador finaliza la escena con una amenaza, los invasores no la cumplieron porque los frailes habían decidido permanecer en el pueblo de Puaray, "contra la recomendación de todos". Mas, hay que preguntarse si el suceso relatado fue realmente una ejecución fingida que se planeó y se ejecutó tal cual se narró, o si fue representada así, lo que tal vez hubiera sido un intento de castigo que quedara frustrado por protesta de los mismos religiosos. De todos modos nos inquieta por varias razones. ¿Realmente fue fingida? ¿O sucedió en primera instancia como intento de ejecución durante el cual los padres salieron a rescatar a los ladrones? ¿Transformó Gallegos el narrador ese intento en algo fingido para promover sus propios fines? Los franciscanos tenían fama de defender a los indios contra los soldados y la evangelización fue el objetivo de la jornada. También pudiera parecer que los franciscanos se aprovecharon de las prácticas de intimidación y violencia de los soldados como oportunidad singular para congraciarse con los habitantes del pueblo. Estas y muchas otras preguntas sobre la expedición quedan sin contestar. Los dos líderes murieron antes de regresar a Santa Bárbara y ninguno de los testimonios juramentados se refieren al episodio, pero Gallegos nos ofrece una cantidad de detalles sobre su escenificación. El narrador sí declara que los padres impidieron que los soldados 
incendiaran el pueblo, sin embargo, la masacre de un pueblo por un grupo de sólo once forasteros entre la numerosa población Tano bien pudiera haber causado su propia extinción. Los españoles estaban ya rumbo de regreso; Fray Santa María había muerto y el texto revela el gran temor que reinaba entre los soldados. Lo sucedido quedará siempre como una especulación. Lo que sí nuestra lectura puede comprobar, sin embargo, es que la dramática manipulación de la violencia y la intimidación formaban parte intrínseca del discurso fronterizo de la negociación cultural.

Cuando los soldados llegaron nuevamente a Santa Bárbara el Domingo de Palmas de abril de 1582, la gente del Gobernador Diego de Ibarra trató de detenerlos para conseguir la información que habían traído sobre la tierra adentro. Pero Gallegos y Bustamante lograron escaparse para seguir su camino hacia la ciudad de México, donde presentaron su informe directamente al Virrey. En la conclusión de su Relación y conçudio, Gallegos retóricamente aplaude la gran hazaña:

por haberse descubierto en tan breve y en su tiempo un negocio como este donde su Magestad y sus vasallos an gastado mucha suma de dinero en busca de este descubrimiento y no se avia topado y nueve hombres aberse atrevido a entrar entre tanto numero de gente como es poblada y la por poblar y haber descubierto lo que se ha descubierto que es la relacion que trayan donde quinientos hombres no la han descubierto ni hallado y los dichos hombres la avian descubiertos a su costa y minicion sin que su Magestad ni otra persona les diese ayuda ni acostamiento ninguno lo cual a dado mucho alibio y animo a muchos de la Nueva España ...(100R).

\section{Conclusiones: "Un murmullo de Palabras"}

Michel de Certeau, en L'écriture de l'histoire nos dice que "el proceso de escribir ... está vinculado al rumor de las palabras que se desvanecen tan pronto como se enuncian y por lo tanto se pierden para siempre. Una pérdida irreparable es la huella de estas voces habladas en los textos en cuyo objeto se han convertido. Por consiguiente es a través de la escritura que se forma nuestra relación con el otro, el pasado". ${ }^{29}$ Aquel "rumor de palabras" que se conservaba en la narración de Alvar Núñez Cabeza de Vaca sobre su travesía por aquellas tierras cuatro décadas antes, eran los que los miembros de la expedición de Rodríguez y Chamuscado leían y escuchaban de nuevo. Para ellos funcionaba como guía de viaje y guión de contactos. Los ecos de aquellos contactos pasados también sonaron de nuevo en la memoria de los pueblos indígenas que encontraron. Y es en esta coyuntura de palabras y memoria que se acunó el guión dramático que sirvió los nuevos y encontrados propósitos de la segunda expedición.

Para Alvar Núñez Cabeza de Vaca, el concepto indígena de los Hijos del Sol había servido de identidad de poder y derecho de paso, ${ }^{30} \mathrm{o}$ tal vez propiciara una negociación de

\footnotetext{
${ }^{29}$ Michel de Certeau, The Writing of History, trans. Tom Conley (New York: Columbia University Press, 1988) 212. L'écriture de l'histoire (Paris: Editions Gallimard, 1975). La traducción al español es nuestra.

${ }^{30}$ Como hemos seffalado en nuestro ensayo, "Cruz y calabaza ..." citado en nota 24.
} 
temor como ha postulado Adorno. ${ }^{31}$ Pero la apropiación de esta identidad por los personajes de la siguiente generación de invasores preparó el escenario para la creación de un nuevo guión que le servía a su nueva agenda ideológica y económica cuyo propósito era abrir los espacios culturales de la frontera norteña para la conversión y la colonización. En realidad la evidencia histórica demuestra que el terror diseminado por la expedición de Rodríguez y Chamuscado provocó violencia por donde pasara. Mas con el motivo de promover su causa ante las autoridades reales, Gallegos plasmó su operación escritural en molde doble: retóricamente, en la providencia de un Dios partidario, y discursivamente, en las glosas y códigos militares y cartográficos de su época - la traducción, la numeración y la denominación de maravillas cuantificables que potenciaban lo convertible y lo explotable. Pues representarlas en glosas, cifras o topónimos intensifica aquella inscripción económica y evangélica que ha sido "guiado por la mano de Dios", como Gallegos la proclamó. Y con ello su mensaje quedaba doblemente anclado en el discurso.

Gallegos también incorporó dos formas embriónicas de los discursos de viaje que podrían constituir otra guía de viaje para regresar a conquistar y convertir Nuevo México - un drama por venir en el cual el narrador se anticipa desde ya en su futuro papel de actor principal. Estos dos elementos son el glosario básico incluido al final de varios capítulos, que hemos mencionado, y el itinerario de los topónimos, ubicación y etnografía de los poblados visitados por la expedición que se expone en el Capítulo XI. Por lo tanto, no nos sorprende saber que la relación inédita de Gallegos fue encontrada en 1602 entre los papeles del Arzobispo y Virrey de México, Pedro Moya de Contreras, junto con los papeles del cosmógrafo real, Enrico Martínez, quien trazó el primer mapa de Nuevo México aquel mismo año. (Gallegos 101V). ${ }^{32}$

En la Relacion y conçudio de Hernán Gallegos, presenciamos cómo la manipulación y omisión del discurso de una generación de exploradores por otra configuraba una nueva guía y un nuevo guión para el acceso a las tierras y pueblos más allá de la frontera del norte de la Nueva España. Si a través de esta operación escrituraria se forma nuestra relación con los acontecimientos de la segunda entrada a Nuevo México, la relación de Gallegos puede leerse como un texto puente entre el pasado mítico y apropriado de Alvar Núñez Cabeza de Vaca y el futuro proyectado de colonización y evangelización que Juan de Oñate y los franciscanos intentarían imponer en las próximas décadas. Los discursos de terror que escenificaron las entradas de los años ochenta engendraron un legado de violencia que irrumpiría a corto plazo en el clima de venganza que la expedición de Espejo encontró al año siguiente, y a largo plazo en la resistencia indígena que al final del siglo XVII estallaría en La Gran Rebelión de los Pueblos cuando se expulsaron a todos los españoles del territorio de Nuevo México por más de cincuenta años. Creemos ver los primeros brotes de esta violencia en el terror escenificado, las identidades prestadas y las amenazas dramatizadas que revelan las fisuras contradictorias de las empresas de minas y misiones novohispanas, glosadas, guiadas y escenificadas desde la frontera del norte por la relación de Hernán Gallegos.

${ }^{31}$ Rolena Adorno, "La Negociación del miedo en Los Naufragios de Cabeza de Vaca, Notas y comentarios sobre Alvar Núñez Cabeza de Vaca, Margo Glantz, coord. (México: Editorial Grijalbo, 1993) 309-350.

${ }^{32}$ El mapa original se conserva en AGI, Mapas y Planos, México 49, y también lo reproduce Hammond y Rey. 
